\title{
Cancer Patients' Preferences for Psychological Counselling: A Cross-Sectional Study Using Full- Profile Conjoint Analysis in Japan
}

Ichikura Kanako ( $\nabla$ ichikura-creha@umin.ac.jp )

Kitasato University School of Allied Health Sciences

Shimizu Sayuri

Yokohama City University

Oshima Noriko

Tokyo Medical and Dental University

Ariizumi Yosuke

Tokyo Medical and Dental University

Fujie Toshihide

Tokyo Metropolitan Ohtsuka Hospital

Yamauchi Shin-ichi

Tokyo Medical and Dental University

Ishikawa Toshiaki

Tokyo Medical and Dental University

Nakajima Yasuaki

Edogawa Hospital

Fukase Yuko

Kitasato University School of Allied Health Sciences

Murayama Norio

Kitasato University School of Allied Health Sciences

Murase Hanako

Kitasato University School of Allied Health Sciences

\section{Tagaya Hirokuni}

Kitasato University School of Allied Health Sciences

Takeuchi Takashi

Tokyo Medical and Dental University

Miyake Satoshi

Tokyo Medical and Dental University

Matsushima Eisuke

Tokyo Medical and Dental University 
Keywords: counselling, counselling, cancer, conjoint analysis, preference

Posted Date: July 27th, 2021

DOI: https://doi.org/10.21203/rs.3.rs-710353/v1

License: (9) This work is licensed under a Creative Commons Attribution 4.0 International License. Read Full License 


\section{Abstract}

Background: Psychological counselling is an effective non-pharmacological intervention for cancer patients facing psychological distress. However, there are barriers to applying counselling in clinical settings because some cancer patients feel that it is a burden and subsequently drop out. This study assessed cancer patients' preferences for psychological counselling using a conjoint analysis approach.

Methods: We conducted a single-center, cross-sectional study using a self-reported questionnaire. The data were collected from outpatients and inpatients at the departments of Respiratory Medicine, Gastrointestinal Surgery, Female Pelvic Surgery, and Head and Neck Surgery from a university hospital between March 2018 and March 2020. The questionnaire, developed from an interview with a clinical psychologist, asked for patients' preferences for counselling with 48 scenarios according to a combination of type, length, price, and frequency. We conducted a conjoint analysis, calculating the relative importance and part-worth value of each factor.

Results: According to the conjoint analysis modeling, cancer patients consider the type as the most important factor when deciding whether to undergo counselling (relative importance: $37.5 \%$ ), followed by frequency (23.4\%), price (19.6\%), and length (19.5\%). Cancer patients value life reviews highly among the four counselling types. However, women and younger patients valued counselling for emotional control the highest, with advanced cancer patients valuing counselling for problem solving the most.

Conclusions: The results reveal that cancer patients consider the type and content of counselling to be the most important factors in the selection process, although preferences depend on individual characteristics. This is the first study to clarify cancer patients' preferences for psychological counselling using conjoint analysis and proposes a new economical method in the psycho-oncology field.

\section{Background}

Cancer is an often fatal and severe medical illness that leads to serious patient burdens. Cancer is one of the most common causes of death internationally, especially in advanced countries [1]. In 2012, cancer accounted for 8.2 million deaths, resulting in $13 \%$ of the total deaths worldwide [2]. In Japan, cancer represents the most prominent cause of death and morbidity, with an estimated 1.0 million new cases and 0.4 million deaths in $2020[3]$.

Many cancer patients experience numerous stressful events during their treatment period, resulting in significant psychological distress. Psychological distress is a collective term that describes patients' commonly experienced mental and emotional burdens, including factors like anxiety, depression, fear, or worry. Developing psychiatric disorders is also a common problem faced by many cancer patients. In fact, $10-20 \%$ of all cancer patients are diagnosed with major depressive disorder, with $20-40 \%$ being diagnosed with depression, including both depressive and adjustment disorders [4, 5]. Facing advanced cancer, its recurrence, being younger, or experiencing physical symptoms are the most common risk factors in the development of psychiatric problems among cancer patients [6]. Additionally, these psychological problems can lead to suicide among cancer patients. The suicide rate of cancer patients is found to be 12.6 times higher than that of healthy people [7]. 
Psychological counselling is the most useful non-pharmacological treatment to help cancer patients in managing their psychological distress [8-10]. Various types of counselling approaches have been developed for use among cancer patients. Previous studies have outlined the efficacy of numerous counselling techniques for cancer patients, such as supportive counselling, cognitive behavioral therapy, and psychoanalytic therapy [8-10]. Additionally, cognitive behavioral therapy includes problem-solving therapy, behavioral interventions, and mindfulness cognitive interventions [11-13].

Psychological counselling has a clear effect on psychological distress in cancer patients. However, there are barriers to applying counselling in a clinical setting. First, meta-analyses demonstrate that there is heterogeneity between studies due to wide variations among the psychotherapeutic interventions studies [10]. Second, the efficacy of psychological counselling depends on the clinical communication and utilization of hybrid skills of the practicing psychologists [14-16]. Third, few studies have described any adverse event data of psychological counselling, although the dropout rate is known to be high according to previous research $[17,18]$. Therefore, an understanding of cancer patients' needs around counselling is still needed to provide a more effective treatment method for their psychological distress.

Therefore, this study aimed to assess cancer patients' preferences for psychological counselling using a conjoint analysis approach. We studied the adequacy of the application of an economic approach to clarify cancer patients' counselling preferences and first conducted a single-centre trials in Japan. This study seeks to provide information to allow for an improved consultation rate of psychological counselling among cancer patients.

\section{Methods}

\section{Study setting and participants}

We conducted a single-center, cross-sectional study using self-reported questionnaires. Patients were recruited from outpatient and inpatient units from a university hospital. The data were collected in the departments of Respiratory Medicine, Gastrointestinal Surgery, Femoral Surgery, and Head and Neck Surgery using selfreported questionnaires between March 2018 and March 2020. We included patients who (a) had cancer diagnoses and (b) were between the ages of 20 and 84 years old. The following patients were excluded from this study: (a) those who declined to participate, (b) those who were diagnosed by their attending doctor with severe physical, mental, or cognitive problems (e.g., serious adverse events, delirium, or dementia), and (c) those who had insufficient literacy skills.

\section{Identifying Attributes}

We conducted a preference elicitation study using semi-structured interviews with ten clinical psychologists who have experience in providing psychological counselling for cancer patients. This qualitative approach has been used in other preference studies to identify key factors $[19,20]$. The interview was composed of the same counselling features that the clinical psychologists would usually provide with their clients, including the following factors: (1) type, (2) content, (3) length, (4) price, and (5) frequency. Each interview's audio was recorded, transcribed, and analyzed using content analysis. The result of this qualitative study suggested that length was shorter and the price was lower in cancer palliative settings than those in a psychiatric setting. 
Based on the psychologist interviews, Table 1 presents the final attributes and levels chosen for the conjoint analysis, with each description used in the questionnaire survey instrument. From the interviews, we combined the type and content of counselling sessions into a single theme, identifying the final four attributes and levels used in our analysis (Table 1). For the interviews, we used 4,000 Japanese yen as a benchmark for the price of counselling, while setting 1,500 Japanese yen as a comparative health treatment price referring to Japanese insurance institutions in cancer palliative settings. In addition, we used 30 minutes as the benchmark in time spent within private room counselling, while setting 10 minutes as the comparative time spent for bedside counselling sessions in a cancer palliative setting. Additionally, a researcher (K.I.) translated and created the English versions of the attribute and level descriptions of the counselling features utilized in this study. A master's student translator, who has been living in English-speaking countries for the past four years, then back-translated the English version into Japanese.

Table 1

Attributes and level descriptions of the counselling features

\begin{tabular}{|c|c|c|}
\hline Attribute & Level & Description \\
\hline \multirow[t]{4}{*}{ Type } & Problem-solving & $\begin{array}{l}\text { Reflect on daily life problems and search for solutions } \\
\text { together. }\end{array}$ \\
\hline & Emotional control & Learn skills to distract from or control one's emotions. \\
\hline & Life review & Review one's life and its purpose or meaning. \\
\hline & Emotional expression & Talk about one's distress or feelings to gain relief. \\
\hline \multirow[t]{2}{*}{ Length } & 10 minutes & \\
\hline & 30 minutes & \\
\hline \multirow[t]{2}{*}{ Price } & 1,500 Japanese yen & \\
\hline & 4,000 Japanese yen & \\
\hline \multirow[t]{3}{*}{ Frequency } & Every two weeks & \\
\hline & Every month & \\
\hline & $\begin{array}{l}\text { Arrange schedules around other } \\
\text { visits }\end{array}$ & \\
\hline
\end{tabular}

\section{Formulating Scenarios}

To create the conjoint analysis choice tasks, we used a full-profile paired comparison. The combination of the four attributes with each level produced $48(4 \times 2 \times 2 \times 3)$ possible scenarios, with it being used across all patterns. The scales and conjoint tasks were presented with careful definitions given for each attribute and specific instructions on how to complete the 5-point Likert scale questions and the conjoint choice tasks.

\section{Clinical characteristics}

We collected both demographic and clinical information from the self-completed questionnaires and the medical records. First, we included the following data: sex, age, place or recruitment, types of cancer, cancer 
stage, onset, treatments, performance status, marriage, education, job, and history of psychiatric treatments. We defined the age between 20 and 59 years old as younger, and stage III or IV cancer as advanced cancer. Second, we asked about patients' desire to attempt psychological counselling using the 5-point Likert scale questionnaire. We originally developed this question for this study.

\section{Sample Size}

The sample size calculation for a conjoint analysis is generally empirically determined because it is dependent on several conditions, such as the number of attributes and levels, as well as the complications of the given task. The sample size of the conjoint analysis ranges from 100 to 300 participants in previous healthcare studies [21]. Therefore, the sample size needed for this study was estimated to be almost 200 participants.

\section{Statistical analyses}

First, we summarized the characteristics of both the participants and hospitals utilizing standard descriptive statistics. Second, we conducted the conjoint analysis and calculated the relative importance and part-worth value of each of the counselling factors. Third, we conducted a subgroup conjoint analysis among participants who were women $(n=86)$, of a younger age $(n=49)$, and had advanced cancer $(n=91)$. All data were analyzed using R version 4.0.2 with the R packages "dplyr," "tidyr," "readr," "readxl," and "conjoint."

\section{Results}

\section{Demographic and clinical characteristics}

Figure 1 is a flow diagram showing the number of study participants included. Of the 218 recruited participants, 189 cancer patients (86.7\%) were included in the conjoint analysis. The study participants' characteristics are listed in Table 2. The sex ratio (men:women) was 1.1:1. One hundred and sixty-one (75.9\%) of the participants were older than 60 years, 171 (80.7\%) were outpatients, $140(68.0 \%)$ were married, and 109 (52.2\%) were unemployed. In addition, $104(49.1 \%)$ were in an advanced stage of cancer, $175(82.5 \%)$ had a high performance status (PS $=0), 152(71.7 \%)$ had undergone surgery, and $107(50.5 \%)$ had undergone chemotherapy.

Table 2 Study participants' Characteristics 


\begin{tabular}{|c|c|}
\hline & $n(\%)$ \\
\hline \multicolumn{2}{|l|}{ Sex } \\
\hline Men & $112(52.8)$ \\
\hline Women & $100(47.2)$ \\
\hline \multicolumn{2}{|l|}{ Age } \\
\hline 20-29 years & $2(0.9)$ \\
\hline $30-39$ years & $4(1.9)$ \\
\hline 40-49 years & $13(6.1)$ \\
\hline $50-59$ years & $32(15.1)$ \\
\hline 60-69 years & $67(31.6)$ \\
\hline $70-79$ years & 80 (37.7) \\
\hline $80-84$ years & $14(6.6)$ \\
\hline \multicolumn{2}{|c|}{ Place of recruitment } \\
\hline Inpatient & 41 (19.3) \\
\hline Outpatient & $171(80.7)$ \\
\hline \multicolumn{2}{|l|}{ Types of cancer } \\
\hline Bowel & $59(27.8)$ \\
\hline Esophagus & $51(24.1)$ \\
\hline Head and neck & $38(17.9)$ \\
\hline Lung & $21(9.9)$ \\
\hline Uterus & $20(9.4)$ \\
\hline Ovary & $15(7.1)$ \\
\hline Thyroid & $5(2.4)$ \\
\hline Other & $3(1.4)$ \\
\hline \multicolumn{2}{|l|}{ Cancer stage } \\
\hline 0 & $16(7.5)$ \\
\hline I & $43(20.3)$ \\
\hline II & $45(21.2)$ \\
\hline III & $56(26.4)$ \\
\hline IV & $46(21.7)$ \\
\hline
\end{tabular}




\begin{tabular}{|c|c|}
\hline \multicolumn{2}{|l|}{ Onset } \\
\hline Primary & $165(77.8)$ \\
\hline Secondary & $47(22.2)$ \\
\hline \multicolumn{2}{|l|}{ Treatments (Overlapped) } \\
\hline Surgery & $152(71.7)$ \\
\hline Chemotherapy & $107(50.5)$ \\
\hline Radiation therapy & $51(24.1)$ \\
\hline \multicolumn{2}{|l|}{ Performance Status } \\
\hline 0 & $175(82.5)$ \\
\hline 1 & $25(11.8)$ \\
\hline 2 & $12(5.7)$ \\
\hline \multicolumn{2}{|l|}{ Marital Status } \\
\hline Single & $66(31.1)$ \\
\hline Married & $140(68.0)$ \\
\hline \multicolumn{2}{|l|}{ Education } \\
\hline Less than high school & $19(9.1)$ \\
\hline High school & $87(41.6)$ \\
\hline 2-year college & $32(15.3)$ \\
\hline 4-year college or postgraduate qualification & $71(34.0)$ \\
\hline \multicolumn{2}{|l|}{ Employment status } \\
\hline Unemployed & $109(52.2)$ \\
\hline Part-time & $23(11.0)$ \\
\hline Full-time & $38(18.2)$ \\
\hline Self-owned or freelance & $29(13.9)$ \\
\hline Others & $10(4.8)$ \\
\hline \multicolumn{2}{|l|}{ Psychiatric treatments (Overlapped) } \\
\hline History of psychiatric visits & $14(6.6)$ \\
\hline History of psychiatric medication & $54(25.5)$ \\
\hline History of psychological counselling & $6(2.8)$ \\
\hline \multicolumn{2}{|l|}{ Desire to attempt psychological counselling } \\
\hline Never want to attempt it & $19(9.0)$ \\
\hline
\end{tabular}


Do not especially want to attempt it

Neither wants to attempt nor reject it

Will attempt it after being encouraged to do so

Want to attempt it
$72(34.0)$

$71(33.5)$

$43(20.3)$

$7(3.3)$

\section{Preferences for clinical counselling}

According to the conjoint analysis model (Fig. 2), the participating patients considered the type of counselling as the most important preference factor (relative importance: $37.5 \%$ ), followed by frequency (23.4\%), price (19.6\%), and length (19.5\%). The subgroup analysis also indicated that counselling type is the most important among women, patients of a younger age, and those at an advanced cancer stage $(35.7 \%, 30.7 \%$, and $38.2 \%$ respectively; Table 3).

Table 3 Subgroup conjoint analysis 


\begin{tabular}{|c|c|c|c|c|c|c|c|c|}
\hline & $\begin{array}{l}\text { All } \\
(n=189)\end{array}$ & & $\begin{array}{l}\text { Women } \\
(n=86)\end{array}$ & & $\begin{array}{l}\text { Younger } \\
(n=49)\end{array}$ & & $\begin{array}{l}\text { Advanced ce } \\
(n=91)\end{array}$ & \\
\hline & $\begin{array}{l}\text { Relative } \\
\text { importance }\end{array}$ & $\begin{array}{l}\text { Part } \\
\text { worth } \\
\text { value }\end{array}$ & $\begin{array}{l}\text { Relative } \\
\text { importance }\end{array}$ & $\begin{array}{l}\text { Part } \\
\text { worth } \\
\text { value }\end{array}$ & $\begin{array}{l}\text { Relative } \\
\text { importance }\end{array}$ & $\begin{array}{l}\text { Part } \\
\text { worth } \\
\text { value }\end{array}$ & $\begin{array}{l}\text { Relative } \\
\text { importance }\end{array}$ & $\begin{array}{l}\text { Part } \\
\text { worth } \\
\text { value }\end{array}$ \\
\hline Type & 37.46 & & 35.68 & & 30.71 & & 38.15 & \\
\hline $\begin{array}{l}\text { Problem- } \\
\text { solving }\end{array}$ & & -.11 & & -.01 & & .02 & & .03 \\
\hline $\begin{array}{l}\text { Emotional } \\
\text { control }\end{array}$ & & -.04 & & .06 & & .07 & & .02 \\
\hline Life review & & .26 & & -.10 & & -.14 & & -.05 \\
\hline $\begin{array}{l}\text { Emotional } \\
\text { expression }\end{array}$ & & -.10 & & .05 & & .05 & & .00 \\
\hline Length & 19.52 & & 19.73 & & 22.29 & & 18.50 & \\
\hline $\begin{array}{l}10 \\
\text { minutes }\end{array}$ & & -.22 & & -.12 & & -.21 & & -.07 \\
\hline $\begin{array}{l}30 \\
\text { minutes }\end{array}$ & & .22 & & .12 & & .21 & & .07 \\
\hline Price & 19.59 & & 20.37 & & 23.16 & & 18.69 & \\
\hline $\begin{array}{l}1,500 \\
\text { Japanese } \\
\text { yen }\end{array}$ & & .21 & & .10 & & .20 & & .07 \\
\hline $\begin{array}{l}4,000 \\
\text { Japanese } \\
\text { yen }\end{array}$ & & -.21 & & -.10 & & -.20 & & -.07 \\
\hline Frequency & 23.43 & & 24.22 & & 23.84 & & 24.65 & \\
\hline $\begin{array}{l}\text { Every two } \\
\text { weeks }\end{array}$ & & -.17 & & -.07 & & -.14 & & -.06 \\
\hline $\begin{array}{l}\text { Every } \\
\text { month }\end{array}$ & & .25 & & .03 & & .05 & & .03 \\
\hline $\begin{array}{l}\text { Arrange } \\
\text { schedules } \\
\text { around } \\
\text { other } \\
\text { visits }\end{array}$ & & -.08 & & .03 & & .09 & & .03 \\
\hline
\end{tabular}

The participating cancer patients valued life reviews highly among the four types of counselling when compared to problem-solving, emotional control, or emotional expression (Fig. 3). However, women and younger age patients valued counselling for emotional control the most, with advanced cancer patients valuing counselling for problem solving the highest (Table 3 ). In addition, all of the participating cancer 
patients valued a 30-minute duration over that of 10 minutes, as well as a price of 1,500 Japanese yen instead of 4,000 Japanese yen (Table 3).

\section{Discussion}

Our study yielded two major findings. First, we observed that the type of counselling was more critical for its selection among cancer patients than was price, length, or frequency. Second, our results demonstrated, in terms of counselling type, that cancer patients prefer life review therapy compared to those involving problem solving, emotional control, or emotional expression. This study was the first notable attempt to explore cancer patients' needs and preferences for counselling in terms of medical services.

One important consequence from this study is that cancer patients choose whether to participate in psychological counselling while emphasising the intervention's content. The issues that cancer patients seek support for are clear among this population, although their perceived needs or worries are often quite different from one another $[22,23]$. In addition, adjustment disorder is the most common psychiatric diagnosis in cancer patients $[24,25]$. Cancer patients often experience clear and specific stressors rather than any original mood symptoms. However, this result may have been affected by either the chosen attributes or levels of the included counselling features. The maximum possible counselling price, 4,000 Japanese yen, is affordable for cancer patients in Japan as it is a financially secure country. Furthermore, the minimum counselling length, 10 minutes, was found to be enough time for the participants of this study who did not have a strong desire to attempt counselling. Additionally, the characteristics of the counselor or counselling room may be a more critical component for cancer patients than the type, length, price, or frequency of counselling. Therefore, this study suggests that the type of counselling is important for cancer patients when choosing whether to undergo this treatment method if no other conditions are being considered.

Another finding was that life review is the most preferred counselling type among cancer patients. Life review provides patients an opportunity to construct positive thoughts about their lives, with it being one of the most effective non-pharmacological interventions, in addition to cognitive-behavioral therapy or mindfulness-based stress reduction $[26,27]$. Most patients will face various inevitable problems related to their disease and will thus require an alternative treatment strategy to maintain their mental health even if they are unfamiliar with psychological interventions. Most of the participants in our study were also at an elderly or retiring age, meaning that they were likely contemplating the end of their lives in some form. Therefore, life review undoubtedly contributes to the reduction of the psychological distress experienced by elderly cancer patients [28]. In this regard, however, the results of our subgroup analyses revealed that cancer patients' preferences for counselling depending on their characteristics, such as their gender, age, or the current state of their disease. Women and younger patients tend to prefer counselling covering emotional control, according to this study's findings. This indicates that these patients hope to gain a sense of control over their emotions, especially when one considers the fact that women and younger patients face a similar risk for psychological distress, including problems like anxiety or depression when dealing with cancer [29,30]. It has been found that most young adult cancer patients and survivors need psychosocial support in the form of health information or in terms of their sexuality problems [31], so that they may focus on resolving their present feelings rather than reviewing those from their past. Conversely, our results also reveal that advanced cancer patients prefer problem-solving in terms of the counselling type. Another study demonstrated patients with 
poor performance statuses have unmet needs in most domains involving physical, psychological, or social problems [32]. Therefore, advanced cancer patients may hope to spend their efforts resolving the physical or social problems at hand, rather than trying to control their psychological distress or review their lives.

In addition, there were no differences found in patients' needs for counselling in all subgroups. The participating cancer patients naturally chose the less expensive counselling option; however, it is difficult to provide counselling at 1,500 Japanese yen given therapists' labor costs. The Japanese government created a national license, entitled "Certified Public Psychologist," for all clinical psychologists in 2019 [33]. The results of our study suggest that there is a compelling need for applied counselling as a healthcare treatment plan for cancer patients.

\section{Study limitations}

Our study has two important limitations. First, there were limitations to the conjoint analysis. As previously noted in the discussion, the type of counselling could not have been the most critical factor in patients' selection of counselling across all participants because this varies depending on the options available. However, we selected the attributes and levels of counselling features in our conjoint analysis based on interview research gained by Japanese clinical psychologists in cancer palliative settings. Second, selection bias might have occurred because of our use of a single-center design in Japan. In this study, the number of breast cancer cases was smaller than that in previous studies. Thus, this may impact the generalizability of our findings. In addition, the number of patients who had an experience with or desire to undergo psychological counselling was especially small in this hospital. However, this was the first study to focus on cancer patients' needs for counselling.

\section{Conclusions}

Our study indicates the possibility that conjoint analysis can apply not to just economic studies but also cancer patients' preference studies. The finding is that most cancer patients consider the type or content of counselling as the most important factor when determining whether or not they wish to receive this treatment form, although their preferences for counselling do depend on their characteristics. This was the first study to clarify cancer patients' preferences for psychological counselling, despite its few methodological limitations.

\section{Abbreviations}

No Abbreviations.

\section{Declarations}

\section{Ethics approval and consent to participate}

All the procedures were in accordance with the ethical standards of the responsible committees on human experimentation (institutional and national) and with the Helsinki Declaration. The study was approved by the independent institutional review board (IRB) of the Tokyo Medical and Dental University (M2017-226). 
Informed consent was obtained, in writing, from all participants after they had received verbal explanations of the study procedure. Participants answered anonymous questionnaires and were identified by code numbers.

\section{Consent for publication}

Not applicable.

\section{Availability of data and materials}

The datasets during and/or analyzed during the current study are available from the corresponding author upon reasonable request.

\section{Competing Interests}

$\mathrm{KI}$ is an advisor of a personal health care services by Clinical Study Support, Inc. YF had received research grants from the Murata Science Foundation. HT is an advisor of a clinical trial by Taisho Pharmaceutical Holdings and a committee member of a Medical Research Ethics Committee of Nikon Corporation and Japan Aerospace Exploration Agency. HM has no competing interests to report.

\section{Funding}

This study was supported by a grant from JSPS KAKENHI (Grant Number: JP16K21016), Kitasato University School of Allied Health Sciences (Grant-in-Aid for Research Project Number: 2018-1044 \& 2020-1032), and scholarship donations from Astellas Pharma Inc., Mitsubishi Tanabe Pharma Corporation, MSD K.K., Otsuka Pharmaceutical, Pfizer Inc., and Takeda Pharmaceutical Company Limited. However, the funders had no role in the study design, data collection, and analysis, decision to publish, or preparation of the manuscript.

\section{Authors' contributions}

IK and ME conceptualized the study. IK, ON, AY, FT, YS, IT, and NY curated the data. IK conducted the formal analysis. IK TH, and MT acquired funding. IK conducted the investigation. IK and SS designed the study methodology. IK oversaw the project administration. IK obtained the study resources. IK and TH ran the software. TT and MH supervised the research. IK validated the study results, created the visualizations, and wrote the original draft. SS, FY, MH, MN, TH, ME reviewed and edited the draft. All authors read and approved the final manuscript.

\section{Acknowledgements}

First, we are grateful to Satoko Ogi and Wakana Takeshita for assisting in recruiting participants. Second, we would like to thank Ryozo Wakabayashi and Tatsuya Isomura from Clinical Study Support, Inc. for conducting the conjoint analysis. Finally, we are grateful to Saori Koga of KOJIMA office for designing and printing the questionnaire of this study, as well as Ryuhei Ichikura for back-translating the English version of the attributes and level descriptions of the studied counselling features.

\section{References}


1. Dagenais GR, Leong DP, Rangarajan S, Lanas F, Lopez-Jaramillo P, Gupta R, Diaz R, Avezum A, Oliveira GBF, Wielgosz A, Parambath SR, Mony P, Alhabib KF, Temizhan A, Ismail N, Chifamba J, Yeates K, Khatib R, Rahman O., ... Yusuf S. Variations in common diseases, hospital admissions, and deaths in middleaged adults in 21 countries from five continents (PURE): a prospective cohort study. Lancet. 2019;365(10226):785-794. doi:10.1016/S0140-6736(19)32007-0

2. World Health Organization. Cancer: Data and Statistics. 2020. https://www.euro.who.int/en/healthtopics/noncommunicable-diseases/cancer/data-and-statistics Accessed 20 January 2021.

3. Ministry of Health Labour and Welfare. Japanese white paper of population -Population Survey Annual Report-. 2011. http://www.mhlw.go.jp/toukei/saikin/hw/jinkou/suii10/ Accessed 20 January 2021.

4. Krebber AMH, Buffart LM, Kleijn G, Riepma IC, de Bree R, Leemans CR, Becker A, Brug J, van Straten A, Cuijpers P, Verdonck-de Leeuw IM. Prevalence of depression in cancer patients: a meta-analysis of diagnostic interviews and self-report instruments. Psycho-Oncology, 2014;23(2):121-130. doi:10.1002/pon.3409

5. Mitchell AJ, Chan M, Bhatti H, Halton M, Grassi L, Johansen C, Meader N. Prevalence of depression, anxiety, and adjustment disorder in oncological, haematological, and palliative-care settings: a metaanalysis of 94 interview-based studies. The Lancet. Oncology. 2011;12(2):160-174. doi:10.1016/S14702045(11)70002-X

6. Miller K, Massie M. Depressive Disorders. In S. W. Breitbart, P. B. Jacobsen, M. J. Loscalzo, R. McCorkle, \& P. N. Butow (Eds.), Psycho-oncology. Oxford University Press; 2010. p. 311-318.

7. Fang F, Fall K, Mittleman MA, Sparén P, Ye W, Adami H-O, Valdimarsdóttir U. Suicide and Cardiovascular Death after a Cancer Diagnosis. New England Journal of Medicine. 2012;366(14):1310-1318. doi:10.1056/NEJMoa1110307

8. Chen YY, Ahmad, M. Effectiveness of adjunct counselling for cancer treatment: a review. Future Oncology. 2018;14(15):1487-1496. doi:10.2217/14796694.3.5.557

9. Guan NC, Mohamed S, Tiah LK, Mun TK, Sulaiman AH, Zainal NZ. Psychotherapy for cancer patients: A systematic review and meta-analysis. The International Journal of Psychiatry Medicine. 2016;51(5):414430. doi:10.1177/0091217416680197

10. Okuyama T, Akechi T, Mackenzie L, Furukawa TA. Counselling for depression among advanced, incurable cancer patients: A systematic review and meta-analysis. Cancer Treatment Reviews. 2017;56:16-27. doi:10.1016/j.ctrv.2017.03.012

11. Finne E, Glausch M, Exner A-K, Sauzet O, Stölzel F, Seidel N. Behavior change techniques for increasing physical activity in cancer survivors: a systematic review and meta-analysis of randomized controlled trials. Cancer Management and Research. 2018;10:5125-5143. doi:10.2147/CMAR.S170064

12. Haller H, Winkler MM, Klose P, Dobos G, Kümmel S, Cramer H. Mindfulness-based interventions for women with breast cancer: an updated systematic review and meta-analysis. Acta Oncologica. 2017;56(12):1665-1676. doi:10.1080/0284186X.2017.1342862

13. Hirai K, Motooka H, Ito N, Wada N, Yoshizaki A, Shiozaki M, Momino K, Okuyama T, Akechi T. ProblemSolving Therapy for Psychological Distress in Japanese Early-stage Breast Cancer Patients. Japanese Journal of Clinical Oncology. 2012;42(12):1168-1174. doi:10.1093/jjco/hys158 
14. McGuinness KM. The prescribing clinical health psychologist: a Hybrid skill set in the new era of integrated healthcare. Journal of Clinical Psychology in Medical Settings. (2012);19(4):434-440. doi:10.1007/s10880-012-9341-0

15. Roos J, Werbart A. Therapist and relationship factors influencing dropout from individual counselling: a literature review. Journal of the Society for Counselling Research. 2013;23(4):394-418. doi:10.1080/10503307.2013.775528

16. Zimmermann D, Rubel J, Page AC, Lutz W. Therapist effects on and predictors of non-consensual dropout in counselling. Clinical Psychology \& Counselling. 2017;24(2):312-321. doi:10.1002/cpp.2022

17. Meister R, Lanio J, Fangmeier T, Härter M, Schramm E, Zobel I, Hautzinger M, Nestoriuc Y, Kriston L. Adverse events during a disorder-specific counselling compared to a nonspecific counselling in patients with chronic depression. Journal of Clinical Psychology. 2020;76(1):7-19. doi:10.1002/jclp.22869

18. Sharf J, Primavera LH, Diener MJ. Dropout and therapeutic alliance: a meta-analysis of adult individual counselling. Counselling. 2020;47(4):637-645. doi:10.1037/a0021175

19. Bridges JFP, Lataille AT, Buttorff C, White S, Niparko JK. Consumer preferences for hearing aid attributes: a comparison of rating and conjoint analysis methods. Trends in Amplification. 2012;16(1):40-48. doi:10.1177/1084713811434617

20. Hofheinz R, Clouth J, Borchardt-Wagner J, Wagner U, Weidling E, Jen MH, Brück P. Patient preferences for palliative treatment of locally advanced or metastatic gastric cancer and adenocarcinoma of the gastroesophageal junction: a choice-based conjoint analysis study from Germany. BMC Cancer. 2016;16(1). doi:10.1186/s12885-016-2975-9.

21. Marshall D, Bridges JFP, Hauber B, Cameron R, Donnalley L, Fyie K, Johnson FR. Conjoint Analysis Applications in Health - How are Studies being Designed and Reported? The Patient: Patient-Centered Outcomes Research. 2010;3(4):249-256. doi:10.2165/11539650-000000000-00000

22. Caruso R, Nanni MG, Riba MB, Sabato S, Grassi L. The burden of psychosocial morbidity related to cancer: patient and family issues. International Review of Psychiatry. 2017;29(5):389-402. doi:10.1080/09540261.2017.1288090

23. Hisamura K, Matsushima E, Tsukayama S, Murakami S, Motoo Y. An exploratory study of social problems experienced by ambulatory cancer patients in Japan: Frequency and association with perceived need for help. Psychooncology. 2018;27(7):1704-1710. doi:10.1002/pon.4703

24. Blazquez MH, Cruzado JA. A longitudinal study on anxiety, depressive and adjustment disorder, suicide ideation and symptoms os emotional distress in patients with cancer undergoing radiotherapy. Journal of Psychosomatic Research. 2016;87:14-21. doi:10.1016/j.jpsychores.2016.05.010

25. van Beek FE, Wijnhoven LMA, Jansen F, Custers JAE, Aukema EJ, Coupe VMH, Cuijpers P, can der Lee ML, Lissenberg-Witte BI, Wijnen B, Prins JB, Verdonck-de Leeuw IM. Prevalence of adjustment disorder among cancer patients, and the reach, effectiveness, cost-utility and budget impact of tailored psychological treatment: study protocol of a randomized controlled trial. BMC Psychology. 2019;7(1). doi:10.1186/s40359-019-0368-y

26. Duncan M, Moschopoulou E, Herrington E, Deane J, Roylance R, Louise J, Bourke L, Morgan A, Chalder T, Thaha MA, Taylor SC, Korszun A, White PD, Bhui K, Investigators S. Review of systematic reviews of non- 
pharmacological interventions to improve quality of life in cancer survivors. BMJ Open.

2017;7(11):e015860. doi:10.1136/bmjopen-2017-015860

27. Zhang X, Xiao H, Chen Y. Effects of life review on mental health and well-being among cancer patients: A systematic review. International Journal of Nursing Studies. 2017;74:138-148.

doi:10.1016/j.ijnurstu.2017.06.01

28. Huang M-H, Wang R-H, Wang H-H. Effect of Life Review on Quality of Life in Terminal Patients: A Systematic Review and Meta-Analysis. Journal of Nursing Research. 2020;28(2):e83.

doi:10.1097/JNR.0000000000000335

29. Erim DO, Bensen JT, Mohler JL, Fontham EH, Song L, Farnan L, Delacroix LE, Peters ES, Erim TN, Chen RC, Gaynes BN. Prevalence and predictors of probable depression in prostate cancer survivors. Cancer. 2019;125(19):3418-3427. doi:10.1002/cncr.32338

30. Faye-Schjoll HH, Schou-Credal I. Pessimism predicts anxiety and depression in breast cancer survivors: A 5-year follow-up study. Psychooncology. 2019;28(6):1314-1320. doi:10.1002/pon.5084

31. Sender A, Friedrich M, Schmidt R, Geue K. Cancer-specific distress, supportive care needs and satisfaction with psychosocial care in young adult cancer survivors. European Journal of Oncology Nursing. 2020;44. doi:10.1016/j.ejon.2019.101708

32. Umezawa S, Fujimori M, Matsushima E, Kinoshita H, Uchitomi Y. Preferences of advanced cancer patients for communication on anticancer treatment cessation and the transition to palliative care. Cancer. 2015;121(23):4240-4249. doi:10.1002/cncr.29635

33. Ministry of Health Labour and Welfare. "Certified Public Psychologist." 2019. https://www.mhlw.go.jp/file/06-Seisakujouhou-12200000-

Shakaiengokyokushougaihokenfukushibu/0000116068.pdf Accessed 20 January 2021.

\section{Figures}

\section{Image not available with this version}

\section{Figure 1}

Flow diagram of the study participants

\section{Image not available with this version}




\section{Figure 2}

Relative importance of the different attributes

\section{Image not available with this version}

\section{Figure 3}

Part worth values of the counselling factors 